\title{
THE MITOCHONDRIAL PROTEIN IMPORT APPARATUS
}

\section{Nikolaus Pfanner and Walter Neupert}

Institut für Physiologische Chemie, Universität München, Goethestr. 33, D-8000 München 2, Federal Republic of Germany

KEY WORDS: precursor proteins, import receptors, mitochondrial contact sites, intramitochondrial sorting, protein transport and unfolding.

\section{CONTENTS}

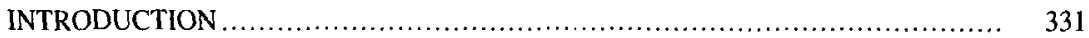

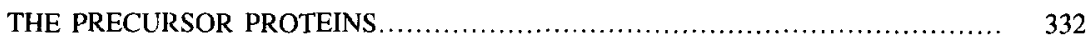

Targeting Signals ........................................................ $\quad 332$

Translocation Competence ...................................................... 335

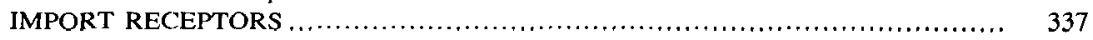

MEMBRANE INSERTION OF PRECURSOR PROTEINS ........................ 340

A General Insertion Protein ........................................................... $\quad 340$

Pathway of Apocytochrome c.......................................................... 342

Partial and Artificial Systems ......................................................... 342

TRANSLOCATION CONTACT SITES ....................................... 343

COVALENT AND NONCOVALENT MODIFICATION OF IMPORTED

PRECURSOR PROTEINS ................................................ 345

Processing Enzymes .......................................................... $\quad 345$

A Folding Machinery ........................................................... 346

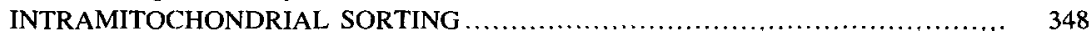

Conservative Sorting ...................................................... 348

Nonconservative Sorting ....................................................... 349

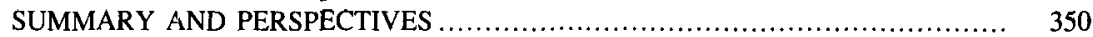

\section{INTRODUCTION}

Mitochondria consist of two membraneous subcompartments (outer membrane and inner membrane) and two aqueous subcompartments (in- 


\section{2}

termembrane space and matrix). Most of the proteins destined for these subcompartments are synthesized on cytosolic polysomes and are imported into the organelle $(1,2)$.

The initial studies on protein transport into mitochondria demonstrated that translocation of the precursor proteins into the membranes is not mechanistically coupled to synthesis of the polypeptide chain on the ribosome, both in vivo and in vitro (3-6). In the following decade, a series of distinct steps of mitochondrial protein import were characterized (Table 1) $(1,2,7)$. Targeting signals in the precursor proteins are recognized by specific receptors on the mitochondrial surface. A loosely folded conformation of the precursor protein is necessary for translocation into the membranes. Import requires energy, ATP, and the membrane potential $\Delta \Psi$ across the inner mitochondrial membrane. Protein transport into or across the inner membrane occurs at contact sites between both mitochondrial membranes. The precursor proteins are proteolytically processed in the mitochondrial matrix and their polypeptide chains are (re)folded. Finally, the proteins are sorted to their respective mitochondrial subcompartment and, in many cases, are assembled into multisubunit complexes.

Only recently, several of the components involved in this translocation process were identified and their structure and function characterized (Table 2 ). This review focuses on the components of the mitochondrial protein import apparatus and thus provides an overview of progress during the past two years.

\section{THE PRECURSOR PROTEINS}

\section{Targeting Signals}

PRESEQUENCES Many imported mitochondrial proteins are synthesized with amino-terminal extrasequences of about 20 to 80 amino acid residues,

Table 1 Steps of mitochondrial protein import

1. Synthesis of precursor proteins on cytosolic polysomes.

2. Maintenance or conferring of translocation-competent (loosely folded) conformation of precursor proteins, possibly by cytosolic factors and ATP.

3. Recognition of targeting signals (often in amino-terminal peptide extensions of the precursor proteins) by specific receptors on the mitochondrial surface.

4. Insertion of precursor proteins into the outer membrane.

5. Transport through contact sites between both mitochondrial membranes, including membrane potential-dependent insertion into the inner membrane.

6. Proteolytic processing (removal of amino-terminal presequence) in the mitochondrial matrix; additional processing events with some precursor proteins.

7. (Re)folding of imported precursor proteins.

8. Sorting of precursor proteins to the mitochondrial subcompartments and assembly. 
Table 2 Identified components of the mitochondrial protein import apparatus ${ }^{\mathrm{a}}$

\begin{tabular}{|c|c|c|c|c|}
\hline Component & Location & Molecular weight & Function & Ref. \\
\hline $\mathrm{Hsp} 70$ & Cytosol & 70,000 (yeast) & $\begin{array}{l}\text { Cytosolic cofactor; stimu- } \\
\text { lates posttranslational } \\
\text { import of precursor } \\
\text { proteins }\end{array}$ & 56,57 \\
\hline MOM19 & Outer membrane & $19,000(N$. crassa $)$ & $\begin{array}{l}\text { Receptor for precursor } \\
\text { proteins with prese- } \\
\text { quence (and other pre- } \\
\text { cursor protcins) }\end{array}$ & 76 \\
\hline MOM72 & Outer membrane & $72,000(N$. crassa $)$ & $\begin{array}{l}\text { Receptor for ADP/ATP } \\
\text { carrier }\end{array}$ & 77 \\
\hline GIP & Outer membrane & $38,000 ?(N$. crassa $)$ & General insertion protein & 80 \\
\hline ISP 42 & Outer membrane & 42,000 (yeast) & Involved in protein import & $85 a$ \\
\hline MPP & Matrix & $\begin{array}{c}57,000(N . \text { crassa) } \\
51,000 \text { (yeast) } \\
55,000 ? \text { (rat liver) }\end{array}$ & $\begin{array}{l}\text { Mitochondrial processing } \\
\text { peptidase }\end{array}$ & $111,112,113$ \\
\hline PEP & $\begin{array}{l}\text { Matrix/inner } \\
\text { membrane }\end{array}$ & $\begin{array}{c}52,000(N . \text { crassa) } \\
48,000 \text { (yeast) } \\
52,000 ? \text { (rat liver) }\end{array}$ & $\begin{array}{l}\text { Processing enhancing } \\
\text { protein }\end{array}$ & $111,112,113$ \\
\hline Hsp60 & Matrix & 60,000 (yeast) & $\begin{array}{l}\text { (Re)folding of imported } \\
\text { proteins }\end{array}$ & 72,133 \\
\hline $\begin{array}{r}\text { Cytochrome } c \\
\text { heme lyase: }\end{array}$ & $\begin{array}{l}\text { Intermembrane } \\
\text { space side }\end{array}$ & $\begin{array}{l}28,000 \text { (yeast) } \\
38,000(N . \text { crassa) }\end{array}$ & $\begin{array}{l}\text { Covalent addition of } \\
\text { heme; essential for im- } \\
\text { port of apocytochrome } c\end{array}$ & $81,90,91,93$ \\
\hline
\end{tabular}

\footnotetext{
${ }^{a}$ Abbreviations: Hsp, heat-shock protein; ISP, import-site protein; MOM, mitochondrial outer membrane protein; $N$. crassa, Neurospora crassa
}

termed presequences. The primary structures of a large number of presequences and detailed mutational analyses of presequences were described recently $(2,8,9)$. Here we give a short overview on the function of presequences, especially with regard to specific recognition of precursor proteins by components of the mitochondrial import apparatus. Presequences carry targeting (signal) information to direct proteins into mitochondria. This was shown mainly by use of hybrid proteins between mitochondrial presequences and nonmitochondrial "passenger" proteins that were imported into mitochondria (10-13). Deletion of the presequences usually prevents uptake of a protein by mitochondria $(8,14)$.

In spite of detailed studies with a large collection of mutated presequences, 


\section{PFANNER \& NEUPERT}

it is still unclear which sequence or structural motif determines the targeting function of mitochondrial presequences. Presequences contain several positively charged amino acid residues and few, if any, negative charges. Secondly, presequences have the tendency to form amphipathic structures upon insertion into lipid membranes (15-19), whereas in an aqueous environment the presequences lack significant secondary structure (15). Replacement of the positive charges by uncharged or negatively charged amino acid residues impairs the mitochondrial import function of a presequence $(8,20-23)$, suggesting a mechanism in which amphipathic structures, having positive charges on one of their sides, are essential for mitochondrial targeting. Several precursor proteins were found to carry redundant targeting information in their amino-terminal portion $(24,25)$.

The analysis of targeting function of prepeptides by mutational variation did not usually lead to unambiguous results. In a number of cases, when such variants were expressed in transformed cells from high-copy-number plasmids, the corresponding protein accumulated to appreciable degrees in the mitochondria. However, the import rates of the same variant precursor proteins into isolated mitochondria were strongly reduced as compared to wildtype $(23,25-27)$. It is doubtful whether accumulation in mitochondria of transformed cells can be taken as a measure of the efficiency of a targeting sequence; on the other hand, import in vitro may suffer from suboptimal conditions.

Experiments with mutated signal sequences involve, of course, the problem that exchange of only one amino acid residue can drastically influence the functional arrangement of other amino acid residues, thus making it very difficult to conclude whether the mutated amino acid residues are directly responsible for the altered import function or not. Furthermore, in most cases it was not clarified whether all the import steps characteristic of authentic mitochondrial precursor proteins are also shared by hybrid proteins or mutated precursor proteins. A striking example of this is given by the observation that nonmitochondrial targeting signals, e.g. a chloroplast transit sequence, could direct proteins into mitochondria in vivo and in vitro albeit with a low efficiency (28-31). A detailed study revealed that a chloroplast signal sequence bypassed the protease-sensitive receptors on the mitochondrial surface and entered the import pathway at a later stage with low efficiency (32). Owing to its very low efficiency, "bypass" import does not disturb the uniqueness of mitochondrial protein composition (33). Indeed, mitochondrial and chloroplast targeting sequences directed attached proteins exclusively to the correct compartment in plant cells (34).

It is conceivable that the positive charges in the mitochondrial targeting sequences are necessary for responding to the electrical potential $\Delta \Psi$ across the inner membrane (35); other motifs that are so far not characterized may 
determine the targeting function of a presequence, i.e. its interaction with the specific receptor.

SIGNALS IN THE MATURE PART OF PRECURSOR PROTEINS Quite a number of mitochondrial proteins are synthesized without a peptide extension (2). Those precursor proteins obviously carry the targeting signal(s) within the mature part of the protein. In few cases, experimental data on the targeting signals of such precursor proteins are available. A 70-kd protein of yeast mitochondrial outer membrane contains a targeting sequence at its extreme amino-terminus $(36,37)$. The inner membrane proteins ADP/ATP carrier and uncoupling protein apparently possess several (at least three) internal targeting signals that are not located at the amino-terminal end (38-40). Targeting signals present in the carboxyl-terminal two thirds of the ADP/ATP carrier polypeptide were shown to employ a specific receptor protein on the mitochondrial surface (38).

Precursor proteins that are synthesized with a presequence might also possess specific targeting function in their mature part. The precursor of an inner membrane protein, subunit 9 of Neurospora crassa $\mathrm{F}_{0} \mathrm{~F}_{1}$-ATPase, secms to carry signals in the mature portion that in concert with the presequence increase the affinity to receptor sites; it was proposed that "assistant sequences" in the mature protein part may enhance the signalling function of presequences (41). Some precursor proteins could be imported, although their presequence had been deleted $(27,42)$. A targeting signal in the mature portion of the cleavable precursor protein to malate dehydrogenase mediated efficient import of the protein in vivo in the absense of the presequence (27). In vitro import of the presequence-deficient "precursor" was undetectable, whereas the presequence-carrying precursor protein was efficiently imported both in vivo and in vitro (see above).

In general, a redundancy of mitochondrial import signals, i.e. the presence of more than one signal in presequence and/or mature protein part, was described for a number of precursor proteins. This redundancy may increase the specificity and efficiency of protein import (33).

Interorganeller misrouting of a protein was reported to be the cause for a genetic disease (43). The normally peroxisomal enzyme alanine/glyoxylate aminotransferase was found in the mitochondria of two patients with primary hyperoxaluria type 1 . This protein targeting defect may be caused by alteration of signals in the precursor protein or mutations of receptor sites on the respective organclles.

\section{Translocation Competence}

UNFOLDING OF PRECURSOR PROTEINS It is generally assumed that proteins are not translocated across biological membranes in their completely 
folded mature conformation. Studies on protein transport into mitochondria provided experimental evidence that the precursor proteins have to be unfolded prior to or during translocation.

1. Precursor proteins can be accumulated in contact sites between both mitochondrial membranes such that the polypeptide chain traverses the two membranes $(44,45)$. The distance spanned by the polypeptide chain is larger than the diameter of the mature folded protein, suggesting that the polypeptide chain is (at least partially) unfolded during translocation. Indeed, by use of a series of hybrid proteins it was found that less than 46 amino acid residues were sufficient to span both mitochondrial membranes (J. Rassow, F.-U. Hartl, B. Guiard, N. Pfanner, W. Neupert, in preparation), indicating a high degree of unfolding of the precursor protein.

2. Induction of a stable tertiary structure in a portion (domain) of a precursor protein prevents import of the precursor into mitochondria. This was most convincingly shown by use of hybrid proteins between a mitochondrial targeting sequence (amino-terminal) and a nonmitochondrial passenger protein (carboxyl-terminal); binding of a specific ligand to the passenger protein promoted its folding to the "mature" conformation and inhibited translocation across the mitochondrial membranes (47-49). In the first experimental demonstration (47), the cytosolic protein dihydrofolate reductase (DHFR) was used as passenger protein. Binding of the specific ligand methotrexate to the DHFR moiety induced the formation of a stable tertiary structure, preventing uptake of the hybrid protein by mitochondria. After release of the ligand, the precursor protein became import-competent. When the amino-terminal portion (derived from a mitochondrial precursor protein) of the hybrid protein was sufficiently long to traverse both mitochondrial membranes, the protein with the folded carboxyl-terminal domain became trapped in mitochondrial contact sites (49). Upon release of the specific ligand, the carboxyl-terminal passenger protein was unfolded on the mitochondrial surface and its translocation into the mitochondrial matrix was completed. This reversible folding demonstrates that unfolding of a precursor protein can occur on the mitochondrial surface.

CYTOSOLIC COFACTORS AND ATP Results of several groups suggested that cytosolic cofactors are important for transport of precursor proteins into mitochondria. These cofactors were only partially characterized, with some indications that they might be of proteinaceous nature (50-55). Recently, 70-kd stress proteins (heat-shock proteins, hsp70) were found to be involved in import of several mitochondrial precursor proteins $(56,57) .70-\mathrm{kd}$ stress proteins are generally ascribed a role in modulating the conformational and aggregational state of proteins in an ATP-dependent manner (58-60), and they might thus be good candidates for factors that confer transport competence to precursor proteins. A further proteinaceous cytosolic factor that is 
inactivated by treatment with $N$-ethylmaleimide seems to participate in protein transport into mitochondria $(57,61)$. On the other hand, purified precursor proteins could be imported in the absence of cytosolic cofactors (47, 62 ), suggesting that the requirement for cofactors is not a general one.

Import of mitochondrial precursor proteins in vitro depends on hydrolysis of nucleoside triphosphates such as ATP (63-65). ATP appears to be involved in conferring translocation competence to precursor proteins: (a) Hybrid proteins with identical targeting signals but various carboxyl-terminal portions require different levels of ATP for import (66). (b) Loosely folded or unfolded precursor proteins require less or no added ATP for transport into mitochondria $(67,68)$. (c) A precursor protein of which an internal tetramerforming sequence was deleted required less ATP for import than the authentic precursor protein that forms a tetramer in the cytosol (69).

The 70-kd stress proteins and other cytosolic cofactors are probably involved in the ATP-dependent process of keeping precursor proteins in a transport-competent state. This most likely includes the prevention of improper interactions of precursor proteins with themselves or with other cytosolic components.

Recent data indicate that the unfolding reaction per se and the translocation across the mitochondrial membranes of some precursor proteins can occur independently of added ATP. Unfolding and membrane translocation of a hybrid protein with a folded carboxyl-terminal portion (derived from DHFR) did not require measurable levels of added ATP (70). This hybrid protein may not require ATP-dependent components to remain in a transport-competent state in the cytosol. The unfolding reaction itself might then be performed by membrane-bound components of the mitochondrial translocation machinery independent of added ATP. Similar results were obtained by G. Schatz and coworkers (71); unfolding of a hybrid protein (containing DHFR) on the mitochondrial surface did not depend on ATP. The completion of transport (including proteolytic processing), however, required ATP. This ATPdependent step may be related to an ATP-requirement in the mitochondrial matrix, especially for interaction with a 60 -kd stress protein (72; see below). This would support the view that not all precursor proteins require ATPdependent cytosolic cofactors, but that some precursor proteins are kept in a transport-competent state by other mechanisms.

\section{IMPORT RECEPTORS}

How is the targeting information of mitochondrial precursor proteins decoded by mitochondria? Functional studies, in particular with Neurospora crassa mitochondria, suggested the existence of distinct specific receptor sites on the mitochondrial surface $(1,2,7)$. Precursor proteins bind with high affinity to 
protease-sensitive sites on the mitochondrial surface $(73,74)$. The precursor proteins are imported from these binding sites without release from the mitochondrial membranes $(54,75)$. Competition studies with various precursor proteins suggested the existence of at least two distinct receptor sites (74). Despite numerous efforts in the last decade, none of the putative receptor sites could be identified. This failure promoted speculations that receptor sites may not be important for mitochondrial protein import $(8,15)$.

Recently, a systematic approach was started in order to identify import receptors for mitochondrial precursor proteins. Gel electrophoretic analysis of the mitochondrial outer membrane from Neurospora crassa leads to resolution of about 25 different proteins. Specific antibodies against most of these proteins were prepared, and their effect on the import of proteins into mitochondria in vitro was tested. Monospecific antibodies against two outer membrane proteins were found to selectively inhibit import of subsets of precursor proteins $(76,77)$.

MOM19 Antibodies or Fab fragments directed against a mitochondrial outer membrane protein of $19 \mathrm{kd}$, termed $M O M 19$, were prebound to isolated mitochondria, and import of various precursor proteins was investigated. Import of most precursor proteins tested, including all those carrying aminoterminal presequences, was inhibited. Inhibition occurred at the level of specific binding of precursor proteins to the mitochondrial surface. Other transport steps such as unfolding of precursor proteins and translocation of precursor proteins from the outer membrane into the inner membrane or matrix were not affected by the antibodies (76). MOM19 is exposed on the mitochondrial surface. Since it exhibits the properties expected of a specific mitochondrial import receptor, it is concluded that MOM19 functions as a specific receptor, especially for precursor proteins with amino-terminal targeting sequences.

Treatment of mitochondria with elastase generated a $17-\mathrm{kd}$ fragment of MOM19. The 17-kd fragment was found to mediate the import of the precursor of $F_{0} F_{1}$-ATPase subunit $\beta$, whereas import of other MOM19dependent precursor proteins was inhibited by the elastase treatment (76). This observation suggests that MOM19 may possess distinct portions for interaction with the various precursor proteins and opens the way for a functional analysis of the MOM19 protein.

MOM72 Antibodies directed against MOM19 did not significantly inhibit the import of the precursor of ADP/ATP carrier (76). Import of this most abundant protein of the inner mitochondrial membrane exhibits several peculiarities (Table 3). The precursor contains (at least) three internal targeting sequences, but none at the amino-terminal end $(38,39)$. ADP/ATP carrier 
appears to employ a different surface receptor as compared to precursor proteins with amino-terminal presequences $(74,76)$. Indeed, antibodies and Fab fragments against a mitochondrial outer membrane protein of $\underline{72} \mathrm{kd}$ (MOM72) inhibit import of ADP/ATP carrier but not of presequence-carrying precursor proteins. The import step affected by the antibodies was found to be the specific binding of ADP/ATP carrier to the mitochondrial surface (77). MOM72 apparently acts as a receptor for the precursor of ADP/ATP carrier. ADP/ATP carrier specifically bound to the mitochondrial surface could be coprecipitated with antibodies against MOM72 after lysis of mitochondria with detergent, strongly supporting the role of MOM72 as high-affinity receptor (77). A large hydrophilic domain of MOM72 protrudes into the cytosol. The hydrophilic domain may carry the binding site for precursor proteins.

The ADP/ATP carrier was most likely not present in the prokaryotic

Table 3 Targeting and sorting pathways of mitochondrial precursor proteins

\begin{tabular}{|c|c|c|c|c|}
\hline & $\begin{array}{l}\text { Precursor proteins with pre- } \\
\text { sequence (e.g. Fe/S protein, } \\
\text { cytochrome } c_{l} \text {, subunits } \beta \\
\text { and } 9 \text { of } \mathrm{F}_{0} \mathrm{~F}_{1}-\mathrm{ATPase} \text { ) }\end{array}$ & $\begin{array}{l}\text { Outer membrane } \\
\text { proteins (e.g. porin, } \\
70-\mathrm{kd} \text { protein) }\end{array}$ & ADP/ATP carrier & Cytochrome $c$ \\
\hline $\begin{array}{l}\text { Amino-terminal } \\
\text { targeting } \\
\text { sequence }\end{array}$ & Yes & $? /$ Yes & No & $?$ \\
\hline Receptor & MOM19 & MOM19 & MOM72 & $\begin{array}{c}\text { No surface } \\
\text { receptor }\end{array}$ \\
\hline $\begin{array}{l}\text { Membrane } \\
\text { insertion }\end{array}$ & GIP & GIP/? & GIP & $\begin{array}{l}\text { Intrinsic } \\
\text { activity } \\
\text { of precursor }\end{array}$ \\
\hline $\begin{array}{l}\text { Transport } \\
\text { through con- } \\
\text { tact sites }\end{array}$ & Yes & (No) & Yes & (No) \\
\hline $\begin{array}{l}\text { Proteolytic } \\
\text { processing }\end{array}$ & Yes & No & No & No \\
\hline Hsp60 involved & Yes & No & No & No \\
\hline Sorting principle & Conservative & - & Nonconservative & - \\
\hline $\begin{array}{l}\text { Prokaryotic } \\
\text { equivalent }\end{array}$ & Yes & $?$ & $(\mathrm{No})$ & Yes \\
\hline
\end{tabular}


ancestor of mitochondria (78). It was probably introduced into the cell during or after endocytosis of the prokaryotic mitochondrial ancestor by the now eukaryotic cell. This may be related to the diverse specificity of MOM19 and MOM72. MOM19 and MOM72 were found to be distributed over the entire mitochondrial surface with a slight (MOM19) and a strong (MOM72) enrichment in regions of contact between both mitochondrial membranes $(76,77)$. Receptors may collect precursor proteins from all over the mitochondrial surface and eventually transfer them to contact sites (79), the major site for translocation of precursor proteins across the mitochondrial membranes (44, 45). MOM19, MOM72, and further components can associate to form multisubunit complexes in the mitochondrial outer membrane (80). These "receptor complexes" are possibly located in contact site regions and may therefore be formed by that fraction of the receptors found in contact sites (see below).

Neither antibodies against MOM19 nor antibodies against MOM72 inhibited the import of apocytochrome $c$, the precursor of cytochrome $c$, to the intermembrane space $(76,77)$. This finding fits well with the previous observation that apocytochrome $c$ does not employ a protease-sensitive surface receptor (81), but most probably inserts spontaneously into the outer membrane (82-84).

\section{MEMBRANE INSERTION OF PRECURSOR PROTEINS}

\section{A General Insertion Protein}

Upon interaction with the specific surface receptor, the precursor proteins are inserted into the mitochondrial outer membrane. By reversible accumulation of precursor proteins at distinct stages of their import pathway (generation of "translocation intermediates"), several transport steps such as binding to receptor sites and transport through contact sites could be characterized in some detail $(44,54,74)$. Another step of transport, insertion of precursor proteins into the outer membrane, was identified, and the existence of a specific site or component that performs the membrane insertion was proposed (54). The number of precursor molecules that can be accumulated at this stage was determined and found to be the same for various precursor proteins $(73,74)$. Competition studies with different precursor proteins suggested that nearly all precursor proteins, with the exception of apocytochrome $c$, used the same sites (74). Precursor proteins accumulated at these sites can be extracted from the membranes by protein denaturants such as sodium carbonate, suggesting a proteinaceous nature of the site $(54,73)$. The site was assumed to function as a common membrane insertion site for precursor proteins and provisionally termed "general insertion protein" (GIP) $(7,74)$ (Figure 1).

As described above, the receptors MOM19 and MOM72 can associate to 


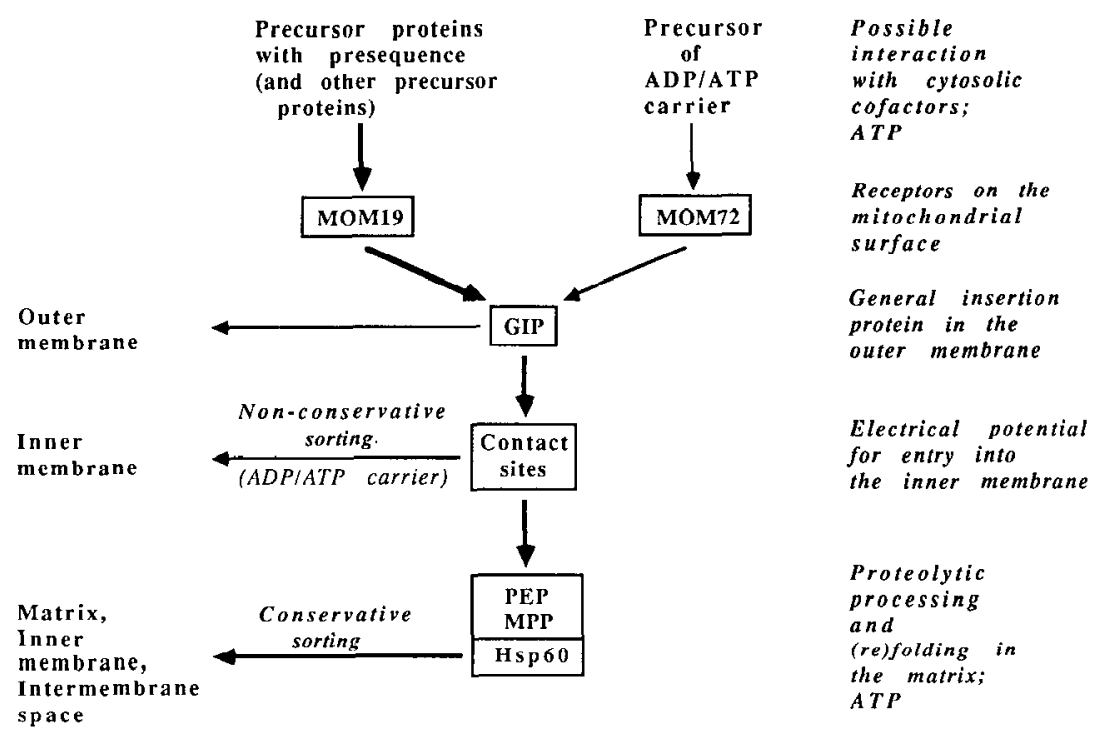

Figure 1 Hypothetical model of protein transport into mitochondria MOM19, mitochondrial outer membrare protein of $19 \mathrm{kd}$; MOM 72 , mitochondrial outer membrane protein of $72 \mathrm{kd}$; GIP, general insertion protein; PEP, processing enhancing protein; MPP, mitochondrial processing peptidase; hsp60, heat-shock protcin of $60 \mathrm{kd}$.

form a multisubunit complex. Precursor proteins accumulated at the GIP site copurify with the receptor complexes, suggesting that GIP is present in these complexes (80). However, MOM19 and MOM72 are degraded by treatment of mitochondria with low concentrations of proteases (such as trypsin) (76, 77), whereas the functionally characterized GIP site is resistant against relatively high concentrations of proteases (54). A further outer membrane protein of $38 \mathrm{kd}$ in Neurospora crassa mitochondria (MOM38) represents a constitutive component of the receptor complexes (80). The protease resistance of MOM38 correlates well with that of the GIP site. MOM38 might therefore be a candidate for GIP (Table 2), although it has to be emphasized that the evidence is indirect.

Antibodies directed against several outer membrane proteins of about $45 \mathrm{kd}$ of yeast mitochondria inhibit import of precursor proteins, suggesting that an outer membrane protein recognized by the antibodies is essential for protein import. Interestingly, the mitochondria had to be pretreated with trypsin in order to efficiently bind the inhibitory antibodies (85), indicating that the functionally relevant antigen is protease resistant. Recently, it was found that the antibody preparation contained contaminating antibodies against an outer membrane protein of $42 \mathrm{kd}$, termed import-site protein 42 or ISP 42 . Inhibition of protein import was indeed caused by the antibodies against ISP 42 and 


\section{PFANNER \& NEUPERT}

not by the antibodies against the 45 -kd proteins (85a). In addition, an artificial precursor protein that was trapped in mitochondrial contact sites could be crosslinked to ISP 42. It is conceivable that MOM38 of Neurospora crassa and ISP 42 of yeast are equivalent proteins and that they are related to GIP.

\section{Pathway of Apocytochrome c}

The import pathway of the intermembrane space protein cytochrome $c$ is unique in several aspects. The presently available experimental evidence suggests the following steps. The precursor protein, apocytochrome $c$, possesses the intrinsic activity to insert into membranes, i.e. without the aid of proteinaceous components $(82-84,86-89)$. Apocytochrome $c$ does not employ a protease-accessible receptor on the mitochondrial surface (81). After insertion of apocytochrome $c$ into the outer membrane, heme is covalently added to the apoprotein by the enzyme cytochrome $c$ heme lyase on the intermembrane space side $(81,90-93)$, and the holoprotein is released to the intermembrane space. Under conditions where the heme group could not be covalently attached to apocytochrome $c$ (e.g. presence of the heme analogue deuterohemin and absence of protoheme), import was arrested at the level of a translocation intermediate: a portion of the precursor protein was still exposed to the cytosol $(94,95)$, whereas another part of the precursor was tightly associated with cytochrome $c$ heme lyase (81); upon addition of protoheme, the prosthetic group was added to the membrane-spanning precursor and the holoprotein was released to the intermembrane space. Apocytochrome $c$ apparently has developed a short-cut pathway as compared to the complex import and sorting pathways followed by other nuclear-coded mitochondrial precursor proteins (Table 3). Interestingly, the membrane insertion activity of apocytochrome $c$ was found to allow circumvention of the receptor/GIP-system by a hybrid protein between a matrix targeting signal and apocytochrome $c$ on its way into the mitochondrial matrix (84).

\section{Partial and Artificial Systems}

PROTEIN TRANSPORT THROUGH THE INNER MEMBRANE In yeast mitochondria with opened outer membrane ("mitoplasts"), precursor proteins can be directly translocated across the inner membrane (96). The precursor proteins thereby bypass the protein import apparatus of the outer membrane. Transport through the inner membrane exhibits some properties of authentic protein import like dependence on a positively charged sequence on the precursor protein, ATP, and the membrane potential $\Delta \Psi$ across the inner membrane (96). This transport process could also be performed with inner membrane vesicles (97). The question remains as to whether the sites for direct translocation across the inner membrane are functionally and structurally related to the authentic import sites (at contact sites between both 
mitochondrial membranes) or if they represent different entities with less importance for physiological import (J. Rassow, N. Pfanner, W. Neupert, in preparation).

INTERACTION OF PRESEQUENCES WITH ARTIFICIAL LIPID MEMBRANES Several laboratories studied the properties of positively charged synthetic peptides resembling mitochondrial presequences. Investigations of the effect of these synthetic peptides on intact mitochondria turned out to be difficult to interpret, since high concentrations of peptides were required to affect protein import and at these concentrations the peptides often uncoupled mitochondria $(19,98)$. Nevertheless, in several cases the presequence peptides apparently specifically inhibited import of precursor proteins $(55,99)$.

With artificial lipid membranes, the presequence peptides were found to be membrane active. Interaction of some, but not all, presequence peptides with the lipid membranes was influenced by an electrical potential across the membrane $(15,19,100)$. These experimental systems obviously do not include the proteinaceous components for initial steps of protein import. High concentrations of the drug adriamycin that binds to acidic phospholipids like cardiolipin inhibit both import of proteins into mitochondria and interaction of a purified precursor protein with lipid membranes $(101,102)$. The significance of these observations for the physiology of protein import, however, is difficult to determine. It remains unclear if precursor proteins directly interact with lipids of the mitochondrial membranes or if the role of lipids is more indirect via effects on embedded proteinaceous components of the import apparatus.

\section{TRANSLOCATION CONTACT SITES}

How are precursor proteins translocated across the two mitochondrial membranes? Butow and colleagues (103) proposed that precursor proteins are imported at sites of close contact between both mitochondrial membranes. It took more than 10 years to obtain experimental evidence for a role of contact sites in protein import. Precursor proteins were reversibly accumulated in contact sites, e.g. by performing import at low temperature in vivo or in vitro (44). The two-membrane spanning topology of this translocation intermediate was demonstrated by accessibility of the accumulated precursor protein to protease on both sides of the two membranes: the presequence was cleaved off by the processing peptidase in the matrix, whereas other (carboxyl-terminal) portions of the precursor proteins were accessible to proteases and also antibodies from outside the mitochondria $(44,45,104)$. Three further procedures to accumulate translocation contact site intermediates were developed: binding of antibodies to carboxyl-terminal parts of the precursor 
proteins prior to import $(44,45)$; lowering of the levels of ATP in the import system $(66,104)$; and, reversible folding of the DHFR domain in a hybrid protein by reversible stabilization with the substrate analogue methotrexate (49). The latter approach could also be used in vivo, when yeast cells were transformed with a plasmid containing the information for such a fusion protein. Contact site intermediates accumulated when the cells were exposed to a folate antagonist (M. Schleyer, W. Neupert, unpublished data).

Labelling of precursor proteins accumulated in contact sites with specific antibodies, and protein $\mathrm{A}$ gold particles confirmed that translocation contact sites are located in the morphologically visible areas of close approximation between both mitochondrial membranes (45). Precursor proteins without a cleavable presequence such as the inner membrane protein ADP/ATP carrier are also imported via contact sites (54), emphasizing the general role of contact sites in protein import (Table 3). Furthermore, Ono \& Tuboi (105) suggested that the outer membrane protein porin is preferentially imported at contact site regions and then distributed over the outer membrane and assembled.

Translocation contact sites can be saturated with precursor proteins. This was achieved by use of large amounts of precursor proteins with a (reversibly or irreversibly) folded carboxyl-terminal portion $(49,106)$. Thereby import of several other precursor proteins was inhibited, suggesting that the various precursor proteins use the same translocation contact sites. Protein transport via contact sites apparently occurs through a hydrophilic membrane environment $(107,108)$. It was proposed that translocation contact sites contain proteinaceous components probably embedded in a perturbed lipid environment (107). Translocation contact sites can be enriched by fractionation of mitochondria into submitochondrial vesicles $(45,109)$, opening the possibility for purification of translocation contact sites.

It is conceivable that structural components (holding the membranes together) form the basis of contact sites and that components of the translocation machinery exhibit a dynamic behavior where only a certain fraction of the transport components is present in contact sites. The transport components present in contact sites may be assembled into a dynamic multisubunit complex (with possible cycles of assembly and disassembly).

Transport of precursor proteins into the inner membrane depends on energization of the membrane. The energy source required is the electrical potential $\Delta \Psi$ and not the $\Delta \mathrm{pH}$ (35). Insertion of a precursor protein into contact sites such that the positively charged presequence crosses the inner membrane requires $\Delta \Psi$; the completion of transport of the precursor protein whereby the major portion of the polypeptide chain is translocated across the inner membrane, however, can occur in the absence of $\Delta \Psi$ (44). The electrical potential (negative inside) may be important for correct positioning of the positively charged presequence in order to allow entry into the inner mem- 
brane (110). Alternatively, $\Delta \Psi$ may be necessary to induce or stabilize the active conformation of a component that is involved in protein entry into the inner membrane.

\section{COVALENT AND NONCOVALENT MODIFICATION OF IMPORTED PRECURSOR PROTEINS}

\section{Processing Enzymes}

PROCESSING PEPTIDASE The presequences are cleaved off by the enzyme processing peptidase in the mitochondrial matrix. The enzyme is dependent on divalent cations such as $\mathrm{Mn}^{2+}$ and $\mathrm{Zn}^{2+}$. Processing peptidase was first purified from Neurospora crassa mitochondria (111). It was found that two proteins were required for processing: the mitochondrial processing peptidase (MPP) and a processing enhancing protein (PEP). These two components have molecular masses of $57 \mathrm{kd}$ and $52 \mathrm{kd}$, respectively. MPP alone has a very low processing activity (111). Subsequently, processing peptidase was purified from yeast mitochondria (112) and rat liver mitochondria (113). In Neurospora crassa, MPP and PEP are recovered as individual proteins during isolation; in yeast and more so in rat liver, the two components form a complex. The amino acid sequences around the cleavage sites of various precursor proteins exhibit common features, especially a positively charged amino acid residue is usually found at position-2 (2nd amino acid residue before the cleavage site) $(2,114)$. Both MPP and PEP are synthesized in the cytosol with presequence; the mature proteins thus perform the proteolytic maturation of their own precursor proteins $(111,115,116)$.

MPP and PEP are the proteins that are affected in two yeast mutants defective in maturation of precursor proteins $(111,112,115,117-119)$. Upon determination of the primary structure of MPP and PEP, several interesting observations were made. A new family of mitochondrial proteins with a function in both biogenesis and bioenergetics was discovered. The members of the family show similarity of their primary structure. MPP, PEP, and the subunits I and II of the $b c_{I}$-complex of the mitochondrial respiratory chain belong, to the family. In Neurospora crassa, but not in yeast, PEP and subunit I are even identical proteins (120). Although the function of subunits I and II has not been exactly determined, they are assumed to participate in assembly and/or stabilization of the $b c_{l}$-complex $(121,122)$. PEP may bind precursor proteins at the matrix side of the inner membrane and present them to MPP. In addition, PEP seems to participate in the translocation of proteins through contact sites (F.-U. Hartl, J. Martin, A. L. Horwich, W. Neupert, in preparation). Four cysteine residues that are conserved in MPP of Neurospora crassa and yeast are not present in PEP. The importance of cysteine residues for the function of MPP is suggested by the inactivation of 


\section{PFANNER \& NEUPERT}

MPP, but not of PEP, by treatment with the sulfhydryl reagent $N$ ethylmaleimide (116).

TWO-STEP PROCESSING Several mitochondrial presequences are proteolytically cleaved in two steps. The first cleavage is always performed by processing peptidase, yielding an intermediate-sized precursor protein. In the case of the precursor of $F_{0} F_{1}$-ATPase subunit 9 , the second cleavage that generates the mature-sized protein is also carried out by processing peptidase (124). A number of precursor proteins have been described that are first cleaved by MPP and in a second step by an enzyme that removes an octapeptide to yield the mature protein. The putative octapeptidyl-peptidase is believed to be located in the matrix $(114,125)$. Most proteins of the intermembrane space studied so far carry a bipartite presequence $(2,8)$. The amino-terminal portion represents a typical positively charged matrix targeting sequence that is removed by processing peptidase. The carboxyl-terminal portion of the presequence is relatively hydrophobic and is responsible for sorting to the intermembrane space $(126,127)$ (see below). Proteolytic removal of these second signals takes place on the intermembrane space side of the inner membrane by one or more processing enzyme(s) (127-129). A yeast mutant affected in the second proteolytic processing of some intermembrane space proteins may be deficient in a processing enzyme (130). So far, none of these enzymes has been identified or characterized.

OTHER MODIFICATIONS Prosthetic groups such as heme, Fe/S clusters, and flavine nucleotides are attached to a number of precursor proteins; furthermore, single amino acid residues can be modified (for a discussion see 2, 9 , 131). For cytochromes $c$ and $c_{l}$, it was demonstrated that the heme had to be in a reduced state prior to its covalent linkage to the apoprotein by specific heme lyases $(92,132)$. Attachment of heme to apocytochrome $c_{I}$ is a prerequisite for the occurrence of the second proteolytic processing step $(128,132)$, indicating a coordinated sequence of the various processing steps.

\section{A Folding Machinery}

Proteins imported into mitochondria are (re)folded to their mature conformation and are often assembled into multisubunit complexes. Recently, a yeast mutant was characterized that is temperature-sensitive defective in assembly of imported mitochondrial proteins (133). Precursor proteins can be imported into the mitochondrial matrix and proteolytically processed; however, their assembly to multisubunit complexes is affected in mitochondria from mutant cells grown at nonpermissive temperaturc. Moreover, retranslocation of proteins from the matrix into or across the inner membrane (see below) is inhibited. The gene affected in this mutant codes for a constitutively ex- 
pressed stress protein ("heat-shock protein") of about $60 \mathrm{kd}$, termed hsp60, that is located in the mitochondrial matrix $(133,134)$. Hsp60 is homologous to the Escherichia coli groEL protein and the chloroplast Rubisco subunitbinding protein $(134,135)$. These three proteins were termed chaperonins $(136,137)$, since they appear to chaperone the assembly of oligomeric protein complexes. In general, heat-shock proteins are thought to play an essential role in modulating conformation and interaction of proteins $(58,138)$, although experimental evidence to support this view is mainly indirect.

Does (re)folding of polypeptides imported into the mitochondrial matrix occur spontaneously or is a folding machinery involved? This was investigated by use of a hybrid protein between a matrix-targeting signal and the passenger protein DHFR. Several in vitro conditions promoted the accumulation of an "unfolded" intermediate of the hybrid protein in the mitochondrial matrix: import at low levels of ATP, low temperature, or presence of a nonhydrolyzable analogue of ATP (the precursor protein had been unfolded by treatment with urea to circumvent a possible unfolding step on the cytosolic side of the membranes) (72). The unfolded state of the imported protein was assessed by digestion with low concentrations of proteases after permeabilization of mitochondria with detergent; the protein imported under control conditions acquired its folded conformation as assayed by resistance to treatment with protease and was present as monomer in the matrix. The unfolded intermediate in the matrix was found to be associated with hsp60 (72). The intermediate accumulated at low levels of ATP could be "chased" to the folded form after addition of ATP and was released from hsp60. This chase by addition of ATP was also possible with an extract prepared from the mitochondrial matrix: the protein was folded and released from hsp60. When hsp60 carrying the unfolded intermediate was partially purified by gel chromatography, readdition of ATP promoted folding of the protein on the surface of hsp60; the folded protein, however, remained associated with hsp60. Additional components that may have been lost during the purification procedure are probably required for the complete sequence of reactions leading to release of the folded protein from hsp60. These results demonstrated that folding of imported proteins in the mitochondrial matrix, at least in many cases, does not occur spontaneously; it requires complex formation with hsp60 and ATP hydrolysis (72). Therefore, hsp60 is not only involved in the folding and assembly pathway of proteins that are integrated into multisubunit complexes (as found for several authentic mitochondrial precursor proteins), it also plays an essential role in (re)folding of monomeric proteins in the mitochondrial matrix.

Several proteins of the intermembrane space require interaction with hsp60 prior to their retranslocation across the inner membrane (133) (see below). These proteins are probably not folded to their mature conformation in the 


\section{PFANNER \& NEUPERT}

matrix; rather hsp60 and further components may induce a conformaton that is conducive to retranslocation across the inner membrane. Future studies are necessary to characterize the various functions of hsp60 and associated components in modulating the conformation of proteins.

\section{INTRAMITOCHONDRIAL SORTING}

Nuclear-encoded mitochondrial proteins have to be sorted to the four mitochondrial subcompartments (outer membrane, intermembrane space, inner membrane, and matrix) (Figure 1). Outer membrane proteins interact with a specific receptor, and then insert and assemble into the outer membrane. Proteins destined for the mitochondrial matrix are translocated through contact sites to their functional destination. The intermembrane space protein cytochrome $c$ has developed a unique import pathway without a proteaseaccessible surface receptor; the precursor protein is directly translocated across the outer membrane (see above). Inner membrane proteins and most intermembrane space proteins follow more complex sorting and assembly pathways that will be discussed in the following paragraphs.

\section{Conservative Sorting}

It was observed that proteins destined for the intermembrane space or the intermembrane space side of the inner membrane are first completely translocated via contact sites into the matrix $(127,139)$. Most of these proteins carry a bipartite presequence. The amino-terminal portion of the presequence functions as a matrix-targeting sequence. After cleavage by processing peptidase, the proteins are retranslocated across the inner membrane to their functional destination. The pathway is in complete agreement with the endosymbiont hypothesis of mitochondrial origin. In the prokaryotic ancestor of mitochondria, all proteins were synthesized in the inner compartment, the equivalent to the mitochondrial matrix. Translocation and assembly pathways of precursor proteins thus had their origin in this compartment. Following endocytosis of the prokaryotic ancestor by the protokaryotic host, most of the genes of the endosymbiont were transferred to the nucleus. The corresponding proteins are now synthesized in the cytosol as precursor proteins with a matrix-targeting sequence. They are imported via contact sites into the matrix space and then use the conserved sorting and assembly pathways established in the prokaryote. This includes their initial interaction with hsp60, the homologue of prokaryotic groEL protein; then they are retranslocated across the inner membrane $(72,133)$ (Table 3$)$. This retranslocation appears to exhibit a number of characteristics of prokaryotic protein export. The carboxylterminal part of the bipartite presequence of several intermembrane space proteins strongly resembles prokaryotic leader sequences $(2,126,127,140)$. 
Originally it was proposed that these relatively hydrophobic sequences function as "stop-transfer" sequences during import at contact sites, thereby anchoring the precursor protein in the inner membrane $(8,126,141-143)$. However, as described above, the precursor proteins are completely transported into the matrix and the hydrophobic sequences appear to direct protein translocation from the matrix across the inner membrane (127). In the retranslocation process, these sequences may in fact be anchored to the inner membrane.

Recently, a quite different import pathway was suggested for a mutated form of cytochrome $c$ peroxidase (144), an intermembrane space protein with a typical bipartite presequence (141). The precursor protein seemed to be imported to the intermembrane space in the absence of $\Delta \Psi$ and was then released from the mitochondria (144). Further studies will be required to analyze the import pathway of authentic cytochrome $c$ peroxidase.

Which sorting pathways are taken by typical inner membrane proteins, i.e. proteins embedded with major portions in the inner membrane? The targeting and sorting signals in the precursor of subunit 9 of Neurospora crassa $\mathrm{F}_{0} \mathrm{~F}_{1}$-ATPase seem to direct the protein on the conservative pathway. The precursor protein is transported via contact sites into the mitochondrial matrix. Upon removal of the positively charged presequence, the protein is retranslocated and assembled into the inner membrane (145). With this protein, the targeting signal for retranslocation apparently resides in the mature part of the protein (145), consistent with the finding that the homologous proteins of yeast and plant mitochondria are synthesized within the organelle and do not carry a cleavable peptide extension $(146,147)$.

Several proteins with mainly hydrophobic character are synthesized within mitochondria. In a series of experiments, it was demonstrated that the (normally mitochondrially encoded) subunits 8 and 9 of yeast $F_{0} F_{1}$-ATPase could be imported and correctly processed by mitochondria (148-150). For this purpose, synthetic "genes" for these subunits were fused to DNA segments coding for a mitochondrial matrix-targeting signal (presequence) and the constructs were expressed in yeast. In the case of subunit 8 , the imported protein was successfully assembled into the $F_{0} F_{1}$-ATPase. Divergence of the genetic code between nucleus and the mitochondria may explain the lack of transfer of the mitochondrial genes for these proteins to the nucleus.

\section{Nonconservative Sorting}

Not all mitochondrial inner membrane proteins are sorted according to the conservative principle. ADP/ATP carrier probably does not possess a prokaryotic equivalent (78); its precursor appears to use a different import and sorting pathway (Table 3; Figure 1). Transport of ADP/ATP carrier from the outer membrane into the inner membrane and assembly to the mature form do not require ATP (66), whereas protein transport via the conservative way 
involves an ATP-dependent step for the interaction with hsp60 in the matrix (72). Indeed, import and assembly of ADP/ATP carrier does not involve hsp60 (145). The precursor of ADP/ATP carrier may diffuse laterally from contact sites to its functional destination in the inner membrane (145).

\section{SUMMARY AND PERSPECTIVES}

Transport of proteins into mitochondria involves a series of functionally defined steps (Table 1). Recently, several of the components of the protein import apparatus were characterized and identified: 70-kd heat-shock protein in the cytosol, two receptors on the mitochondrial surface, an outer membrane protein of $42 \mathrm{kd}$, processing peptidase, processing enhancing protein (PEP), and the $60-\mathrm{kd}$ heat-shock protein hsp60 in the matrix, as well as cytochrome $c$ heme lyase.

Future studies will focus on three lines of experiments. (a) A detailed analysis of structure and function of the identified components and of the precursor proteins. (b) Identification and characterization of further components of the import apparatus, including additional cytosolic factors, components of translocation contact sites, factors that cooperate with hsp60, components involved in the retranslocation across the inner membrane, and a number of enzymes for modification of precursor proteins, such as processing enzymes in the matrix and intermembrane space as well as enzymes for addition of prosthetic groups. (c) Reconstitution of partial reactions of mitochondrial protein import with purified components. A complete reconstitution of the chain of reactions leading to transport and assembly of mitochondrial precursor proteins will require much further work.

\section{ACKNOWLEDGMENTS}

We thank Thomas Söllner for critical comments on the manuscript.

\section{Literature Cited}

1. Attardi, G., Schatz, G. 1988. Annu. Rev. Cell Biol. 4:289-333

2. Hartl, F.-U., Pfanner, N., Nicholson, D. W., Neupert, W. 1989. Biochim. Biophys. Acta 988:1-45

3. Hallermayer, G., Neupert, W. 1976. Genetics and Biogenesis of Chloroplasts and Mitochondria, ed. T. Bücher, W. Neupert, W. Sebald, S. Werner, pp. 807-12. Amsterdam: North-Holland

4. Harmey, M. A., Hallermayer, G., Neupert, W. 1976. See Ref. 3, pp. 81318

5. Hallermayer, G., Zimmermann, R., Neupert, W. 1977. Eur. J. Biochem. 81:523-32
6. Harmey, M. A., Hallermayer, G., Korb, H., Neupert, W. 1977. Eur. J. Biochem. 81:533-44

7. Pfanner, N., Hartl, F.-U., Neupert, W. 1988. Eur. J. Biochem. 175:205-12

8. Hurt, E. C., van Loon, A. P. G. M. 1986. Trends Biochem. Sci, 11:204 7

9. Nicholson, D. W., Neupert, W. 1988. Protein Transfer and Organelle Biogenesis, ed. R. C. Das, P. W. Robbins, pp. 677-746. New York: Academic

10. Hurt, E. C., Pesold-Hurt, B., Schatz, G. 1984. FEBS Lett. 178:306-10

11. Horwich, A. L., Kalousek, F., Mell- 
man, I., Rosenberg, L. E. 1985. EMBO J. 4:1129-35

12. Hurt, E. C., Pesold-Hurt, B., Suda, K., Oppliger, W., Schatz, G. 1985. EMBO J. 4:2051-68

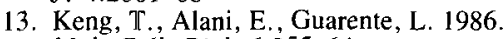
Mol. Cell. Biol. 6:355-64

14. van Loon, A. P. G. M., Young, E. T 1986. EMBO J. 5:161-65

15. Roise, D., Horvath, S. J., Tomich, J. M., Richards, J. H., Schatz, G. 1986. EMBO J. 5:1327-34

16. von Heijne, G. 1986. EMBO J. 5:133542

17. Kraus, J. P., Novotny, J., Kalousek, F., Swaroop, M., Rosenberg, L. E. 1988. Proc. Natl. Acad. Sci. USA 85:8905-9

18. Roise, D., Theiler, F., Horvath, S. J., Tomich, J. M., Richards, J. H., et al. 1988. EMBO J. 7:649-53

19. Roise, D., Schatz, G. 1988. J. Biol. Chem, 263:4509-11

20. Horwich, A. L., Kalousek, F., Rosenberg, L. E. 1985. Proc. Natl. Acad. Sci. USA 82:4930-33

21. Horwich, A. L., Kalousek, F., Fenton, W. A., Pollock, R. A., Rosenberg, L. E. 1986. Cell 44:451-59

22. Horwich, A. L., Kalousek, F., Fenton, W. A., Furtak, K., Pollock, R. A., Rosenberg, L. E. 1987. J. Cell Biol. 105:669--77

23. Bedwell, D. M., Strobel, S. A., Yun, K., Jongeward, G. D., Emr, S. D. 1989. Mol. Cell. Biol. 9:1014-25

24. Pilgrim, D., Young, E. T. 1987. Mol. Cell. Biol. 7:294-304

25. Bedwell, D. M., Klionsky, D. J., Emr, S. D. 1987. Mol. Cell. Biol. 7:4038-47

26. Isaya, G., Fenton, W. A., Hendrick, J. P., Furtak, K., Kalousek, F., Rosenberg, L. E. 1988. Mol. Cell. Biol. 8:5150-58

27. Thompson, L. M., McAlister-Henn, L. 1989. J. Biol. Chem. 264:12091-96

28. Hurt, E. C., Soltanifar, N., Goldschmidt-Clermont, M., Rochaix, J.-D., Schatz, G. 1986. EMBO J. 5:1343-50

29. Allison, D. C., Schatz, G. 1986. Proc. Natl. Acad. Sci. USA 83:9011-15

30. Baker, A., Schatz, G. 1987. Proc. Natl. Acad. Sci. USA 84:3117-21

31. Hurt, E. C., Schatz, G. 1987. Nature 325:499-503

32. Pfaller, R., Pfanner, N., Neupert, W. 1989. J. Biol. Chem. 264:34-39

33. Pfanner, N., Pfaller, R., Neupert, W. 1988. Trends Biochem. Sci. 13:165-67

34. Boutry, M., Nagy, F., Poulsen, C., Aoyagi, K., Chua, N.-H. 1987. Nature 328:340-42

35. Pfanner, N., Neupert, W. 1985. EMBO J. $4: 2819-25$
36. Hase, T., Müller, U., Riezman, H., Schatz, G. 1984. EMBO J. 3:315764

37. Hurt, E. C., Müller, U., Schatz, G. 1985. EMBO J. 4:3509-18

38. Pfanner, N., Hoeben, P., Tropschug, M., Neupert, W. 1987. J. Biol. Chem. 262:14851-54

39. Smagula, C. S., Douglas, M. G. 1988. J. Cell. Biochem. 36:323-27

40. Liu, X. Q., Bell, A. W., Freeman, K. B., Shore, G. C. 1988. J. Cell. Biol. 107:503-9

41. Pfanner, N., Müller, H. K., Harmey, M. A., Neupert, W. 1987. EMBO J. 6:3449-54

42. Volland, C., Urban-Grimal, D. 1988. J. Biol. Chem. 263:8294-99

43. Danpure, C. J., Cooper, P. J., Wise, P. J., Jennings, P. R. 1989. J. Cell Biol. 108:1345-52

44. Schleyer, M., Neupert, W. 1985. Cell 43:339-50

45. Schwaiger, M., Herzog, V., Neupert, W. 1987. J. Cell Biol. 105:235-46

46. Deleted in proof

47. Eilers, M., Schatz, G. 1986. Nature 322:228--32

48. Chen, W.-J., Douglas, M. G. 1987. J. Biol. Chem. 272:15605-9

49. Rassow, J., Guiard, B., Wienhues, U., Herzog, V., Hartl, F.-U., Neupert, W. 1989. J. Cell Biol. 109:1421-28

50. Argan, C., Lusty, C. J., Shore, G. C. 1983. J. Biol. Chem. 258:6667-70

51. Miura, S., Mori, M., Tatibana, M. 1983. J. Biol. Chem. 258:6671-74

52. Ohta, S., Schatz, G. 1984. EMBO J. 3:651-57

53. Argan, C., Shore, G. C. 1985 Biochem. Biophys. Res. Commun. 131:289-98

54. Pfanner, N., Neupert, W. 1987. J. Biol. Chem. 262:7528-36

55. Ono, H., Tuboi, S. 1988. J. Biol Chem. 263:3188-93

56. Deshaies, R. J., Koch, B. D., WernerWashburne, M., Craig, E. A., Schek man, R. 1988. Nature $332: 800-5$

57. Murakami, H., Pain, D., Blobel, G. 1988. J. Cell Biol. 107:2051-57

58. Pelham, H. R. B. 1986. Cell 46:959-61

59. Pelham, H. R. B. 1988. Nature 332: 776-77

60. Flynn, G. C., Chappell, T. G., Rothman, J. E. 1989. Science 245:385-90

61. Randall, S. K., Shore, G. C. 1989. FEBS Lett. 250:561-64

62. Pfaller, R., Freitag, H., Harmey, M. A., Benz, R., Neupert, W. 1985. J. Biol. Chem. 260:8188-93

63. Pfanner, N., Neupert, W. 1986. FEBS Lett. 209:152-56 
64. Eilers, M., Oppliger, W., Schatz, G. 1987. EMBO J. 6:1073-77

65. Chen, W.-J., Douglas, M. G. 1987. Cell 49:651-58

66. Pfanner, N., Tropschug, M., Neupert, W. 1987. Cell 49:815-23

67. Verner, K., Schatz, G. 1987. EMBO J. 6:2449-56

68. Pfanner, N., Pfaller, R., Kleene, R. Ito, M., Tropschug, M., Neupert, W. 1988. J. Biol. Chem. 263:4049-51

69. Chen, W.-J., Douglas, M. G. 1988. J. Biol. Chem. 263:4997-5000

70. Pfanner, N., Rassow, J., Guiard, B., Söllner, T., Hartl, F.-U., Neupert, W. 1990. Submitted

71. Eilers, M., Hwang, S., Schatz, G. 1988. EMBO J. 7:1139-45

72. Ostermann, J., Horwich, A. L., Neupert, W., Hartl, F.-U. 1989. Nature 341:125-30

73. Pfaller, R., Neupert, W. 1987. EMBO J. $6: 2635-42$

74. Pfaller, R., Steger, H. F., Rassow, J., Pfanner, N., Neupert, W. 1988. J. Cell Biol. 107:2483-90

75. Zwizinski, C., Schleyer, M., Neupert, W. 1983. J. Biol. Chem. 258:4071-74

76. Söllner, T., Griffiths, G., Pfaller, R., Pfanner, N., Neupert, W. 1989. Cell 59:1061-70

77. Söllner, T., Pfaller, R., Griffiths, G., Pfanner, N., Neupert, W. 1990. Submitted

78. Klingenberg, M. 1985. Ann. NY Acad. Sci. 456:279-88

79. Pfanner, N., Neupert, W. 1990. Curr. Top. Membr. Transp. 36: In press

80. Pfaller, R., Söllner, T., Griffiths, G., Pfanner, N., Neupert, W. 1990. Submitted

81. Nicholson, D. W., Hergersberg, C., Neupert, W. 1988. J. Biol. Chem. 263:19034-42

82. Dumont, M. E., Richards, F. M. 1984. J. Biol. Chem. 259:4147-56

83. Rietveld, A., Ponjee, G. A. E., Schiffers, P., Jordi, W., Van De Coolwijk, P. J. F. M., et al. 1985. Biochim. Biophys. Acta 818:398-409

84. Stuart, R. A., Nicholson, D. W., Neupert, W. 1990. Cell 60: In press

85. Ohba, M., Schatz, G. 1987. EMBO J. 6:2109-15

85a. Vestweber, D., Brunner, J., Baker, A., Schatz, G. 1989. Nature 341:205-9

86. Rietveld, A., Berkhout, T. A., Roenhorst, A., Marsh, D., de Kruijff, B. 1986. Biochim. Biophys. Acta $858: 38-46$

87. Rietveld, A., Jordi, W., de Kruijff, B. 1986. J. Biol. Chem. 261:3846-56

88. Berkhout, T. A., Rietveld, A., de
Kruijff, B. 1987. Biochim. Biophys. Acta 897:1-4

89. Jordi, W., Li-Xin, Z., Pilon, M., Demel, R. A., de Kruijff, B. 1989. J. Biol. Chem. 264:2292-301

90. Dumont, M. E., Ernst, J. F., Hampsey, D. M., Sherman, F. 1987. EMBO J. 6:235-41

91. Nargang, F. E., Drygas, M. E., Kwong, P. L., Nicholson, D. W., Neupert, W' 1988. J. Biol. Chem. 263:9388-94

92. Nicholson, D. W., Neupert, W. 1989 Proc. Natl. Acad. Sci. USA 86:434044

93. Drygas, M. E., Lambowitz, A. M., Nargang, F. E. 1989. J. Biol. Chem. 264: In press

94. Hennig, B., Neupert, W. 1981. Eur. J. Biochem. 121:203-12

95. Hennig, B., Koehler, H., Neupert, W. 1983. Proc. Natl. Acad. Sci. USA 80:4963-67

96. Ohba, M., Schatz, G, 1987. EMBO J. 6:2117-22

97. Hwang, S., Jascur, T., Vestweber, D., Pon, L., Schatz, G. 1989. J. Cell Biol. 109:487-93

98. Ito, A., Ogishima, T., Ou, W., Omura, T., Aoyagi, H., et al. 1985. J. Biochem. 98:1571-82

99. Furuya, S., Okada, M., Ito, A., Aoyagi, H., Kanmera, T., et al. 1987. $J$. Biochem. 102:821-32

100. Skerjanc, I. S., Shore, G. C., Silvius, J. R. 1987. EMBO J. 6:3117-23

101. Eilers, M., Endo, T., Schatz, G. 1989. J. Biol. Chem. 264:2945-50

102. Endo, T., Eilers, M., Schatz, G. 1989. J. Biol. Chem. 264:2951-56

103. Kellems, R. E., Allison, V. F., Butow, R. A. 1975. J. Cell Biol. 65:1-14

104. Söllner, T., Pfanner, N., Neupert, W. 1988. FEBS Lett. 229:25-29

105. Ono, H., Tuboi, S. 1987. Eur. J. Biochem. 168:509-14

106. Vestweber, D., Schatz, G. 1988. J. Cell Biol. 107:2037-43

107. Pfanner, N., Hartl, F.-U., Guiard, B., Neupert, W. 1987. Eur. J. Biochem. 169:289-93

108. Vestweber, D., Schatz, G. 1988. J. Cell Biol. 107:2045-49

109. Pon, L. A., Moll, T., Vestweber, D., Marshallsay, B., Schatz, G. 1989. $J$. Cell Biol. 109:2603-16

110. Pfanner, N., Neupert, W. 1988. The Roots of Modern Biochemistry, ed. $\mathrm{H}$. Kleinkauf, H. von Döhren, L. Jaenicke, pp. 707-12. Berlin: de Gruyter

111. Hawlitschek, G., Schneider, H., Schmidt, B., Tropschug, M., Hartl, F.U., Neupert, W. 1988. Cell 53:795-806

112. Yang, M., Jensen, R. E., Yaffe, M. P., 
Oppliger, W., Schatz, G. 1988. EMBO J. 7:3857-62

113. Ou, W.-J., Ito, A., Okazaki, H., Omura, T. 1989. EMBO J. 8:2605-12

114. Hendrick, J. P., Hodges, P. E., Rosenberg, L. E. 1989. Proc. Natl. Acad. Sci. USA 86:4056-60

115. Witte, C., Jensen, R. E., Yaffe, M. P., Schatz, G. 1988. EMBO J. 7:1439-47

116. Schneider, H., Arretz, M., Wachter, E., Neupert, W. 1990. Submitted

117. Yaffe, M. P., Schatz, G. 1984. Proc. Natl. Acad. Sci. USA 81:4819-23

118. Pollock, R. A., Hartl, F.-U., Cheng, M. Y., Ostermann, J., Horwich, A. L., Neupert., W. 1988. EMBO J. 7:3493500

119. Jensen, R. E., Yaffe, M. P. 1988. EMBO J. 7:3863-71

120. Schulte. U., Arretz, M., Schneider, H., Tropschug, M., Wachter, E., et al. 1989. Nature 339:147-49

121. Tzagoloff, A., Wu, M., Crivellone, $M$. 1986. J. Biol. Chem. 261:17163-69

122. Oudshoorn, P., van Steeg, H., Swinkels, B. W., Schoppink, P., Grivell, L. A. 1987. Eur. J. Biochem. 163:97-103

123. Deleted in proof

124. Schmidt, B., Wachter, E., Sebald, W., Neupert, W. 1984. Eur. J. Biochem. 144:581-88

125. Kalousek, F., Hendrick, J. P., Rosenberg, L. E. 1988. Proc. Natl Acad. Sci. USA $85: 7536-40$

126. van Loon, A. P. G. M., Brändli, A. W., Schatz, G. 1986. Cell 44:801-12

127. Hartl, F.-U., Ostermann, J., Guiard, B., Neupert, W. 1987. Cell 51:1027-37

128. Gasser, S. M., Ohashi, A., Daum, G., Böhni, P. C., Gibson, J., et al. 1982. Proc. Natl. Acad. Sci. USA 79:267-71

129. Teintze, M., Slaughter, M., Weiss, H., Neupert, W. 1982. J. Biol. Chem. 257:10364-71

130. Pratje, E., Guiard, B. 1986. EMBO J. 5:1313-17

131. Hay, R., Böhni, P., Gasser, S. 1984. Biochim. Biophys. Acta 779:65-87
132. Nicholson, D. W., Stuart, R. A., Neupert, W. 1989. J. Biol. Chem. 264:10156-68

133. Cheng, M. Y., Hartl, F.-U., Martin, J., Pollock, R. A., Kalousek, F., et al. 1989. Nature 337:620-25

134. Reading, D. S., Hallberg, R. L., Myers, A. M. 1989. Nature 337:655-59

135. Hemmingsen, S. M., Woolford, C., van der Vies, S. M., Tilly, K, Dennis, D. T., et al. 1988. Nature 333:330-34

136. Ellis, R. J. 1987. Nature 328:378-79

137. Ellis, R. J., Hemmingsen, S. M. 1989. Trends Biochem. Sci, 14:339-42

138. Rothman, J. E. 1989. Cell 59:591-601

139. Hartl, F.-U., Schmidt, B., Wachter, E., Weiss, H., Neupert, W. 1986. Cell 47:939-51

140. Wickner, W. T., Lodish, H. F. 1985. Science 230:400-7

141. Kaput, J., Goltz. S., Blobel, G. 1982. J. Biol. Chem. 257:15054-58

142. van Loon, A. P. G. M., Schatz, G 1987. EMBO J. 6:2441-48

143. van Loon, A. P. G. M., Brändli, A. W., Pesold-Hurt, B., Blank, D., Schatz, G. 1987. EMBO J. 6:2433-39

144. Kaput, J., Brandriss, M. C., PrussakWieckowska, T. 1989. J. Cell Biol. 109:101-12

145. Mahlke, K., Pfanner, N., Martin, J., Horwich, A. L., Hartl, F.-U., Neupert, W. 1990. Submitted.

146. Hensgens, L. A. M., Grivell, L. A., Borst, P., Bos, J. L. 1979. Proc. Natl. Acad. Sci. USA 76:1663-67

147. Dewey, R. E., Schuster, A. M., Levings, C. S. III, Timothy, D. H. 1985. Proc Natl Acad Sci USA 82:101519

148. Nagley, P., Farrell, L. B., Gearing, D. P., Nero, D., Meltzer, S., Devenish, R. J. 1988. Proc. Natl. Acad. Sci. USA 85:2091-95

149. Farrell, L. B., Gearing, D. P., Nagley, P. 1988. Eur. J. Biochem. 173:131-37

150. Nagley, P., Devenish, R. J. 1989. Trends Biochem. Sci. 14:31-35 
Annual Review of Biochemistry
Volume 59, 1990

\section{CONTENTS}

How to Succeed in Research Without Being a Genius, Oliver H. Lowry

Pyruvoyl-Dependent Enzymes, Paul D. van Poelje and Esmond E. Snell

Phytochelatins, Wilfried E. Rauser

Recent Topics in Pyridoxal 5'-Phosphate Enzyme Studies,

Hideyuki Hayashi, Hiroshi Wada, Tohru Yoshimura, Nobuyoshi Esaki, and Kenji Soda

Selenium Biochemistry, Thressa $C$. Stadtman

Biochemistry of Endotoxins, Christian R. H. Raetz

Occluded Cations in Active Transport, Ian M. Glynn and S. J. D. Karlish

Chemical Nucleases: New Reagents in Molecular Biology, David S. Sigman and Chi-hong B. Chen

Cadherins: A Molecular Family Important in Selective Cell-Cell Adhesion, Masatoshi Takeichi

Structure, Function, and Diversity of Class I Major Histocompatibility Complex Molecules, Pamela J. Bjorkman and Peter Parham

DNA Helicases, Steven W. Matson and Kathleen A. Kaiser-Rogers

The Mitochondrial Protein Import Apparatus, Nikolaus Pfanner and Walter Neupert

Unusual Coenzymes of Methanogenesis, Anthony A. DiMarco, Thomas A. Bobik, and Ralph S. Wolfe

Peptides from Frog Skin, Charles L. Bevins and Michael A.

Zasloff

Clathrin and Associated Assembly and Disassembly Proteins, James $H$. Keen

Antib̀ody-Antigen Complexes, David R. Davies, Eduardo A. Padlan, and Steven Sheriff 
T Cell Receptor Gene Diversity and Selection, Mark $M$. Davis

The Bacterial Phosphoenolpyruvate:Glycose

Phosphotransferase System, Norman D. Meadow, Donna $K$.

Fox, and Saul Roseman

Self-Splicing of Group I Introns, Thomas $R$. Cech

Structure AND Function of Cytochrome $c$ OXIDAse, Roderick A. Capaldi

Transition-State Analogues in Protein Crystallography:

Probes of the Structural Source of Enzyme Catalysis, Elias Lolis and Gregory A. Petsko

Intermediates in the Folding Reactions of Small Proteins, Peter S. Kim and Robert L. Baldwin

Regulation of Vaccinia Virus Transcription, Bernard Moss

Biochemical Aspects of Obesity, Henry Lardy and Earl Shrago

RNA Polymerase B (II) and General Transcription Factors, Michèle Sawadogo and André Sentenac

Sequence-Directed Curvature of DNA, Paul J. Hagerman

CYTOKINES: COORDINATORS OF IMMUNE AND INFLAMMATORY

Responses, Ken-ichi Arai, Frank Lee, Atsushi Miyajima, S.

Miyatake, Naoko Arai, and Takashi Yokota

The Family of Collagen Genes, Eero Vuorio and Benoit de Crombrugghe

Defense-Related Proteins in Higher Plants, Dianna J. Bowles

Motor Proteins of Cytoplasmic Microtubules, Richard B. Vallee and Howard S. Shpetner

DNA Recognition by Proteins with the Helix-Turn-Helix

Motif, Stephen C. Harrison and Aneel K. Aggarwal

cAMP-Dependent Protein Kinase: Framework for a Diverse

FAMILy of Regulatory EnZymes, Susan S. Taylor, Joseph A.

Buechler, and Wes Yonemoto

The Classification and Origins of Protein Folding Patterns, Cyrus Chothia and Alexei V. Finkelstein

INDEXES

Author Index

Subject Index

Cumulative Index of Contributing Authors, Volumes 55-59

Cumulative Index of Chapter Titles, Volumes 55-59 